Published in final edited form as:

Curr Opin Pediatr. 2015 February ; 27(1): 110-115. doi:10.1097/MOP.0000000000000184.

\title{
Importance of Viruses in Acute Otitis Media
}

\author{
Johanna Nokso-Koivisto, MD, PhD ${ }^{1}$, Tal Marom, MD $^{2}$, and Tasnee Chonmaitree, MD $^{3}$ \\ ${ }^{1}$ Department of Otorhinolaryngology, Helsinki University Central Hospital, Helsinki, Finland \\ ${ }^{2}$ Department of Otolaryngology-Head and Neck Surgery, Edith Wolfson Medical Center, Tel Aviv \\ University Sackler School of Medicine, Holon, Israel ${ }^{3}$ Division of Infectious Diseases, Department \\ of Pediatrics, University of Texas Medical Branch, Galveston, TX, United States
}

\begin{abstract}
Purpose of review-Acute otitis media (AOM) occurs as a complication of viral upper respiratory tract infection (URI). Bacterial otopathogens and respiratory viruses interact and play important roles in AOM development. Better understanding of viral and bacterial interactions may lead to innovative ways to lessen the burden of this common childhood disease.
\end{abstract}

Recent findings-There has been increasing evidence that AOM occurs during URI, even in the absence of nasopharyngeal bacterial colonization. Among the types of viruses associated with AOM, respiratory syncytial virus continues to be the most commonly detected. It is still unclear whether viral load plays an important role in AOM development, but symptomatic URI (as opposed to asymptomatic viral infection) is crucial. Widespread use of bacterial and viral vaccines in young children, including pneumococcal conjugate and influenza vaccines, has led to the reduction in otitis media-related health care use between 2001 and 2011. There has been no new vaccine against respiratory viruses other than influenza.

Summary-Progress has been made towards reduction of the burden of AOM in the last decade. Success in reducing AOM incidence will rely mainly on prevention of nasopharyngeal otopathogen colonization, as well as reduction in the incidence of viral URI.

\section{Keywords}

Acute otitis media; respiratory viruses; viral-bacterial interactions; respiratory syncytial virus; rhinoviruses

\section{Introduction}

Acute otitis media (AOM) is one of the most common diseases in children and the most frequent reason for antimicrobial prescriptions in high-resource countries. It is currently acknowledged that AOM is a bacterial complication of viral upper respiratory tract infection (URI), however, viruses alone can cause AOM. The high incidence of AOM results from the

Corresponding Author: Johanna Nokso-Koivisto, MD, PhD, Department of Otorhinolaryngology, Helsinki University Central Hospital, P.O. Box 220, 00290 Helsinki, Finland, johanna.nokso-koivisto@ hus.fi.

No conflicts of interest 
exceedingly high burden of viral URIs. About $35 \%$ of URI episodes are complicated by AOM, occurring mainly within the first week of URI onset $(1,2)$. In the last 15 years, medical progress has been made towards the prevention of AOM, which has led to the reduction of otitis visit rates to the physicians and in antibiotics prescriptions $(3,4)$. This was attributed to the widespread use of bacterial and viral vaccines, and the introduction of the observation option in mild to moderate AOM cases without initial antibiotic treatment (5). Bacterial vaccine against Streptococcus pneumoniae, the leading AOM pathogenic bacteria, was first introduced in 2000. Since then, pneumococcal conjugate vaccines have been implemented into many national immunization programs worldwide (4). Concurrently, routine influenza vaccination in children has been recommended in the last decade. Influenza vaccines have been shown to effectively prevent seasonal influenza and influenzaassociated AOM, and early treatment in the course of influenza with antiviral therapy also reduced AOM complication rates (6-9). In this article, we review the current literature related to the importance of respiratory viruses in AOM, and discuss how the increased knowledge in this area may lead to better prevention strategies for further reduction of AOM burden.

\section{Respiratory viruses}

Viral respiratory infections are the most common diseases in children around the world. Although some of the recently discovered respiratory viruses (e.g., coronaviruses of the Severe Acute Respiratory Syndrome, SARS, and the Middle East Respiratory Syndrome, MERS) have gained a lot of publicity (10), common respiratory viruses still have remarkably more impact on human health worldwide. Viral URI is usually mild and selflimiting, but the universality of the disease causes remarkable economic impact and burden (11). In addition, URI is often complicated by bacterial infections such as AOM, acute sinusitis or pneumonia requiring antibiotic treatment (12). In high-resource countries, public concern over viral epidemics can greatly affect and lead to increased economic costs. For example, the 2009 influenza A/H1N1 pandemic resulted in an increase in parent-initiated visits due to respiratory symptoms for healthy infants in their first year of life (13), probably because of increased parental anxiety. Yet, the influenza pandemic had no impact on the overall viral epidemiology of respiratory infections in these infants.

Multiple respiratory viruses are of hundreds of different serotypes; these viruses can cause the common cold, or URI (Table 1). Rhinoviruses and coronaviruses (229E, OC43 and NL63) are the most common causes of URI. Other virus groups that also cause URI may have distinct features, for example, respiratory syncytial virus (RSV) is the leading cause for severe bronchiolitis requiring hospitalization among neonates and infants; influenza viruses cause yearly epidemics with potentially severe respiratory symptoms and complications; and parainfluenza viruses are commonly associated with acute laryngitis. Relatively new respiratory viruses such as human bocaviruses and metapneumoviruses have also been shown to cause URI and AOM in children (14-17). Although human bocavirus type 1 causes primarily respiratory infections, virus shedding can persist in the nasopharynx for a long period; therefore the overall significance of this virus in respiratory infections is still unclear $(15,17)$. 


\section{Pathogenesis of virus-induced AOM}

AOM usually occurs concurrently or just after URI; more than $90 \%$ of children with AOM have concurrent URI symptoms. The three most common bacterial otopathogens: $S$. pneumoniae, nontypeable Haemophilus influenzae, and Moraxella catarrhalis colonize the infant's nasopharynx from early age, and do not infect the respiratory tract or cause symptoms until viral URI (nasopharyngitis) occurs, causing changes of the nasopharyngeal milieu. The coexistence of bacterial otopathogens and the complex interactions between bacteria and respiratory viruses effect on the URI course and eventually on AOM outcome (18-20). Earlier reports from experimental animal models, in vitro studies, studies of adult volunteers infected with respiratory viruses, and studies of children with URI have led to the understanding of essential steps in the pathogenesis of AOM development after URI (Figure 1). Respiratory viruses cause inflammation of the nasopharynx and the Eustachian tube, generating host immune and inflammatory responses, including the generation of cytokines, chemokines and inflammatory mediators. Viral infections also increase nasopharyngeal colonization and adherence of bacteria to epithelial cells. The chemical and immunological properties of the secreted substances alter the mucous property and diminish the normal mucociliary clearance of the nasopharyngeal and tympanomastoid mucosal cells. Eustachian tube dysfunction/obstruction and negative middle ear pressure then occur, facilitating the entrance of both colonized bacteria and respiratory viruses from the nasopharynx into the middle ear cavity. The middle ear inflammation follows, leading to middle ear fluid accumulation, increased middle ear pressure, and signs and symptoms of AOM develop. A strong evidence for the important role of viruses is the findings that at the time of AOM, respiratory viruses are detected in majority of nasopharyngeal specimens and up to $70 \%$ middle ear fluid samples (21).

\section{Viruses as AOM pathogens}

Although AOM is often bacterial or viral-bacterial co-infection, there is evidence that respiratory virus alone, without co-infecting bacteria, can cause AOM. Experimental studies in adults and in chinchillas have shown that induced virus infection can lead to the development of AOM. Revai et al. reported that $10 \%$ of children with AOM had no detectable bacterial pathogens colonized in the nasopharynx, suggesting that these are cases of viral AOM (22). Ruohola et al recently reported an increased risk of AOM in cases infected with RSV, without colonized bacteria (19). Further evidence of viral AOM has emerged from viruses or viral nucleic acids being detected from middle ear fluid of children with AOM in absence of bacteria (23-25).

Although any virus that causes URI can lead to AOM, it has been suggested that certain viruses are more likely to cause AOM than others, e.g. more 'ototropic'. Among the common respiratory viruses, RSV has always been identified as AOM-associated virus, while results on AOM associated with other viruses have not been consistent. In a prospective study of 294 young children, we reported increased AOM risks with URI associated with RSV, coronaviruses, adenoviruses, and human bocavirus $(1,17)$. Because of the high prevalence of rhinovirus-URI in general, even without an increased rate of AOM development after URI, rhinoviruses are also considered common AOM-associated viruses. 
In a study by Wiertesema et al, rhinoviruses, human bocaviruses, parainfluenza viruses, adenoviruses and RSV were detected significantly more often in the nasopharynx of children with a history of recurrent AOM, compared to healthy children controls (23). In a recent report, results of respiratory virus testing of more than 96,000 specimens from children during 9 respiratory seasons showed that detection of RSV, human metapneumovirus and influenza was temporally associated with increased diagnoses of $\operatorname{AOM}(26)$.

With the widespread use of molecular diagnostics, respiratory viruses have been detected in up to $50 \%$ of asymptomatic young children. Our most recent study described 403 asymptomatic viral infections in 237 infants (27). While the overall rate of AOM following URI in the first year of life was $27 \%$, no AOM had occurred following asymptomatic viral infections. This interesting finding highlights the fact that AOM development following URI requires an inflammation severe enough to initiate the expression of URI symptoms, which is also likely to be associated with Eustachian tube dysfunction. Other risk factors than severity of viral infections are likely to also play role in AOM development.

\section{AOM risk factors}

Why only one in three young children develops AOM after URI and the other two do not may depend on numerous factors. It is clear that AOM is a multifactorial disease; important risk factors include type and dose of the pathogen(s), environmental factors, such as feeding type, cigarette smoke exposure and daycare attendance, and the individual genetic risks. Recurrent AOM and/or otitis proneness is associated with familial tendency, specific ethnic populations, and specific single nucleotide polymorphisms of cytokine/chemokine genes (28-32). Individuals may have different genetic susceptibilities to respiratory infections and different immune responses to infections, which have an effect to the susceptibility for the development of AOM complication. However, the large variety of different cytokines, chemokines and the possible polymorphic genes make this entity difficult and complex to study. Research in this field has just scratched the surface.

The most important risk factors for AOM development are the colonized bacterial otopathogens in the nasopharynx, the presence of respiratory viruses and their complex interactions (33). In children with URI, those who are colonized with otopathogens are more likely to have concomitant AOM than those who are not (19); AOM risk differs by the specific viruses and bacteria involved. Recent studies have aimed to determine the "threshold" of bacterial and viral loads that are sufficient enough to cause AOM; the results so far have been conflicting. In a study of Australian indigenous children with AOM, nasopharyngeal nontypeable $H$. influenzae load was significantly elevated in the presence of enterovirus and coronavirus, and loads of $M$. catarrhalisand nontypeable $H$. influenzae were higher when multiple viruses were detected (34). At no point were the individual bacterial loads lower in the presence of a respiratory virus. Pettigrew et al demonstrated that children with high RSV loads in nasopharyngeal samples had an increased AOM risk, and AOM risk was independently associated with high RSV viral load with $S$. pneumonia and nontypeable $H$. influenzae (20). The risk was higher for the presence of bocavirus and nontypeable $H$. influenzae together. In a recent study (27), higher viral loads were found in nasopharyngeal 
specimens from infants with symptomatic URI associated with RSV, rhinoviruses, human metapneumovirus, adenovirus, parainfluenza viruses 1 and 3, coronaviruses, enteroviruses, and bocavirus, compared to viral loads in asymptomatic viral infections. Interestingly, viral loads did not differ between viral URI with and without AOM. These findings imply the important influence of other multiple risk factors for AOM development.

\section{Clinical implications}

The knowledge on the importance of viruses in AOM has clinical implications, specifically on the treatment and prevention. Because respiratory viruses usually co-infect with bacteria in the middle ear, AOM is often not a 'pure bacterial disease'. Nevertheless, in studies for which AOM diagnostic criteria were stringent, bacterial pathogens were isolated from the middle ear fluid in high proportion of the cases (e.g. 80-90\%), mostly with the 3 otopathogens singly or in combination. In children with AOM, respiratory viruses have been identified from middle ear fluid in 20-70\% of cases using conventional and molecular diagnostic methods. At present, the antimicrobial treatment available for AOM includes only antibiotics; as viral infection is generally self-limited, no antiviral drug is recommended.

Some cases of AOM may not require antibiotic because AOM may be a 'pure viral infection', or because the middle ear exudate containing bacteria (e.g. pus) may drain via the Eustachian tubes once their function returns to normal (a few to several days). Based on recent studies, including clinical trials for which stringent criteria for AOM diagnosis were applied $(35,36)$, the American Academy of Pediatrics has updated the clinical practice guideline on diagnosis and treatment of AOM in 2013 (5). Initial antibiotic therapy is now recommended only in infants and children with severe symptoms of AOM or if they present with otorrhea, presumably with rupture of the tympanic membrane. Children with nonsevere symptoms, including those younger than 2 years of age with unilateral AOM, may be observed without antibiotic initially. For prevention purposes, the overall goal is to reduce or prevent nasopharyngeal colonization of bacterial otopathogens, and prevent young children from having viral URI. While the importance of reducing environmental risks cannot be over emphasized, the use of bacterial and viral vaccines will likely make a significant impact. Of the 3 otopathogens, only vaccines against $S$. pneumoniae are currently available. Pre-licensure controlled studies of pneumococcal conjugate vaccine for 7 serotypes (PCV-7) have shown $6-8 \%$ reduction of AOM in vaccinated children, compared to controls. The reduction of AOM in the 2000's may have been the result of PCV-7 and influenza vaccine use, plus other factors such as parents' education towards reducing AOM risk factors and physicians' effort to minimize AOM over-diagnosis. The licensure of the current pneumococcal vaccine (PCV-13) in 2010 in the United States, with a broader coverage for 6 additional serotypes, has further reduced otitis media-related healthcare use (4).

Prevention of viral URI is complicated because of the variety of numerous respiratory virus types that are associated with URI. Nevertheless, progress has been made through the use of influenza vaccines, the only available respiratory virus vaccines to date. Since early 1990's, investigators have shown that trivalent, inactivated influenza vaccines and later, liveattenuated influenza vaccine have effectively prevented AOM during influenza seasons (6, 7). The vaccines work through preventing influenza illness and influenza-associated AOM. 
Therefore, the efficacy/effectiveness in AOM prevention vary from year to year, depending on the efficacy of the vaccine against influenza illnesses, which ties to the level of influenza activity in the community and how good match the vaccines are for the circulating strains. The higher influenza activity in the season, the higher likelihood the 'good-matched' vaccines will be more effective in preventing influenza and influenza-associated AOM when compared to controls. In addition, there has been studies on prevention of AOM by early treatment of influenza in children, which showed that treatment with oral oseltamivir significantly reduced new AOM in young children with laboratory-confirmed influenza infection (9). Prevention of AOM through the use of respiratory viral vaccines has a potential to be more effective with the availability of vaccines against for more common AOM-associated viruses with such as RSV. However, despite decades of RSV vaccine research, no RSV vaccine has been developed to phase III clinical trials to date. Any future progress to be made towards vaccination against common respiratory viruses will have an impact on reducing the burden of AOM.

\section{Conclusions}

While bacterial otopathogens colonize the nasopharynx from early age, symptomatic viral URI is needed to initiate the development of AOM. In 5-10\% of cases, AOM occurs in the absence of detectable colonizing pathogenic bacteria. A variety of common respiratory viruses play important role in the pathogenesis and interact with bacteria during AOM. Successful prevention of the disease will rely on prevention of nasopharyngeal bacterial colonization, as well as reduction of viral URI incidence.

\section{Acknowledgments}

This work is supported in part by the grants R01 DC 005841 and UL1 TR00071 from the National Institutes of Health.

\section{References}

1. Chonmaitree T, Revai K, Grady JJ, Clos A, Patel JA, Nair S, et al. Viral upper respiratory tract infection and otitis media complication in young children. Clin Infect Dis. 2008; 46(6):815-23. [PubMed: 18279042]

2. Kalu SU, Ataya RS, McCormick DP, Patel JA, Revai K, Chonmaitree T. Clinical spectrum of acute otitis media complicating upper respiratory tract viral infection. Pediatr Infect Dis J. 2011; 30(2): 95-9. [PubMed: 20711085]

3. Grijalva CG, Nuorti JP, Griffin MR. Antibiotic prescription rates for acute respiratory tract infections in US ambulatory settings. JAMA. 2009; 302(7):758-66. [PubMed: 19690308]

4*. Marom T, Tan A, Wilkinson GS, Pierson KS, Freeman JL, Chonmaitree T. Trends in otitis mediarelated health care use in the United States, 2001-2011. JAMA Pediatr. 2014; 168(1):68-75. This article reports the most recent downward trend in otitis media-related healthcare use, mainly from pneumococcal conjugate vaccines but the trend likely incorporated the effect of influenza vaccination and other factors also. [PubMed: 24276262]

5. Lieberthal AS, Carroll AE, Chonmaitree T, Ganiats TG, Hoberman A, Jackson MA, et al. The diagnosis and management of acute otitis media. Pediatrics. 2013; 131(3):e964-99. [PubMed: 23439909]

6. Block SL, Heikkinen T, Toback SL, Zheng W, Ambrose CS. The efficacy of live attenuated influenza vaccine against influenza-associated acute otitis media in children. Pediatr Infect Dis J. 2011; 30(3):203-7. [PubMed: 20935591] 
7. Heikkinen T, Block SL, Toback SL, Wu X, Ambrose CS. Effectiveness of intranasal live attenuated influenza vaccine against all-cause acute otitis media in children. Pediatr Infect Dis J. 2013; 32(6): 669-74. [PubMed: 23271441]

8. Heinonen S, Silvennoinen H, Lehtinen P, Vainionpää R, Vahlberg T, Ziegler T, et al. Early oseltamivir treatment of influenza in children 1-3 years of age: a randomized controlled trial. Clin Infect Dis. 2010; 51(8):887-94. [PubMed: 20815736]

9. Winther B, Block SL, Reisinger K, Dutkowski R. Impact of oseltamivir treatment on the incidence and course of acute otitis media in children with influenza. Int J Pediatr Otorhinolaryngol. 2010; 74(6):684-8. [PubMed: 20363510]

10. Bialek SR, Allen D, Alvarado-Ramy F, Arthur R, Balajee A, Bell D, et al. First confirmed cases of Middle East respiratory syndrome coronavirus (MERS-CoV) infection in the United States, updated information on the epidemiology of MERS-CoV infection, and guidance for the public, clinicians, and public health authorities - May 2014. MMWR Morb Mortal Wkly Rep. 2014; 63(19):431-6. [PubMed: 24827411]

11. Yin JK, Salkeld G, Lambert SB, Dierig A, Heron L, Leask J, et al. Estimates and determinants of economic impacts from influenza-like illnesses caused by respiratory viruses in Australian children attending childcare: a cohort study. Influenza Other Respir Viruses. 2013; 7(6):1103-12. [PubMed: 23829670]

12. Marom T, Alvarez-Fernandez PE, Jennings K, Patel JA, McCormick DP, Chonmaitree T. Acute Bacterial Sinusitis Complicating Viral Upper Respiratory Tract Infection in Young Children. Pediatr Infect Dis J. 2014

13. Ede LC, Loeffelholz MJ, Alvarez-Fernandez P, Pong DL, Patel JA, McCormick DP, et al. Effect of the 2009 Influenza A/H1N1 Pandemic on Viral Respiratory Infections in the First Year of Life. Pediatr Infect Dis J. 2012; 31(11):1107-12. [PubMed: 22596088]

14. Adams O, Weis J, Jasinska K, Vogel M, Tenenbaum T. Comparison of human metapneumovirus, respiratory syncytial virus and Rhinovirus respiratory tract infections in young children admitted to hospital. J Med Virol. 2014

15. Meriluoto M, Hedman L, Tanner L, Simell V, Mäkinen M, Simell S, et al. Association of human bocavirus 1 infection with respiratory disease in childhood follow-up study, Finland. Emerg Infect Dis. 2012; 18(2):264-71. [PubMed: 22305021]

16. Nokso-Koivisto J, Pyles RB, Miller AL, Patel JA, Loeffelholz M, Chonmaitree T. Viral load and acute otitis media development after human metapneumovirus upper respiratory tract infection. Pediatr Infect Dis J. 2012; 31(7):763-6. [PubMed: 22411051]

17*. Nokso-Koivisto JPR, Miller A, Jennings K, Loeffelholz MJ, Chonmaitree T. Role of Human Bocavirus in Upper Respiratory Tract Infections and Acute Otitis Media. J Pediatr Infect Dis Soc. 2014; 3(2):98-103. A study reporting relative importance of human bocavirus in AOM, among various common respiratory viruses.

18. Verhoeven D, Xu Q, Pichichero ME. Differential impact of respiratory syncytial virus and parainfluenza virus on the frequency of acute otitis media is explained by lower adaptive and innate immune responses in otitis-prone children. Clin Infect Dis. 2014; 59(3):376-83. [PubMed: 24785236]

19**. Ruohola A, Pettigrew MM, Lindholm L, Jalava J, Räisänen KS, Vainionpää R, et al. Bacterial and viral interactions within the nasopharynx contribute to the risk of acute otitis media. J Infect. 2013; 66(3):247-54. This article reports several cases of AOM concurrent with URI, without nasopharyngeal bacterial colinization. They also found RSV as a significant risk for AOM in absence of nasopharyngeal bacteria. [PubMed: 23266462]

20. Pettigrew MM, Gent JF, Pyles RB, Miller AL, Nokso-Koivisto J, Chonmaitree T. Viral-bacterial interactions and risk of acute otitis media complicating upper respiratory tract infection. J Clin Microbiol. 2011; 49(11):3750-5. [PubMed: 21900518]

21. Ruohola A, Meurman O, Nikkari S, Skottman T, Salmi A, Waris M, et al. Microbiology of acute otitis media in children with tympanostomy tubes: prevalences of bacteria and viruses. Clin Infect Dis. 2006; 43(11):1417-22. [PubMed: 17083014]

22. Revai K, Dobbs LA, Nair S, Patel JA, Grady JJ, Chonmaitree T. Incidence of acute otitis media and sinusitis complicating upper respiratory tract infection: the effect of age. Pediatrics. 2007; 119(6):e1408-12. [PubMed: 17545367] 
23. Wiertsema SP, Chidlow GR, Kirkham LA, Corscadden KJ, Mowe EN, Vijayasekaran S, et al. High detection rates of nucleic acids of a wide range of respiratory viruses in the nasopharynx and the middle ear of children with a history of recurrent acute otitis media. J Med Virol. 2011; 83(11): 2008-17. [PubMed: 21915878]

24. Nokso-Koivisto J, Räty R, Blomqvist S, Kleemola M, Syrjänen R, Pitkäranta A, et al. Presence of specific viruses in the middle ear fluids and respiratory secretions of young children with acute otitis media. J Med Virol. 2004; 72(2):241-8. [PubMed: 14695665]

25. Heikkinen T, Thint M, Chonmaitree T. Prevalence of various respiratory viruses in the middle ear during acute otitis media. N Engl J Med. 1999; 340(4):260-4. [PubMed: 9920949]

26. Stockmann C, Ampofo K, Hersh AL, Carleton ST, Korgenski K, Sheng X, et al. Seasonality of acute otitis media and the role of respiratory viral activity in children. Pediatr Infect Dis J. 2013; 32(4):314-9. [PubMed: 23249910]

27**. Chonmaitree T, Alvarez-Fernandez PE, Kristofer K, Trujillo R, Marom T, Loeffelholz MJ, et al. Symptomatic and asymptomatic respiratory viral infections in the first year of life: Association with acute otitis media. Clinical infectious Diseases. 2014 Sep 9. This is a recent, large prospective study of infants in the first year of life. The study shows that asymptomatic respiratory viral infection does not lead to AOM and viral load in URI with and without AOM is not sinificantly different.

28. Patel JA, Nair S, Revai K, Grady J, Saeed K, Matalon R, et al. Association of proinflammatory cytokine gene polymorphisms with susceptibility to otitis media. Pediatrics. 2006; 118(6):2273-9. [PubMed: 17142509]

29. Revai K, Patel JA, Grady JJ, Nair S, Matalon R, Chonmaitree T. Association between cytokine gene polymorphisms and risk for upper respiratory tract infection and acute otitis media. Clin Infect Dis. 2009; 49(2):257-61. [PubMed: 19522649]

30. Alper CM, Winther B, Hendley JO, Doyle WJ. Cytokine polymorphisms predict the frequency of otitis media as a complication of rhinovirus and RSV infections in children. Eur Arch Otorhinolaryngol. 2009; 266(2):199-205. [PubMed: 18560870]

31. Emonts M, Veenhoven RH, Wiertsema SP, Houwing-Duistermaat JJ, Walraven V, de Groot R, et al. Genetic polymorphisms in immunoresponse genes TNFA, IL6, IL10, and TLR4 are associated with recurrent acute otitis media. Pediatrics. 2007; 120(4):814-23. [PubMed: 17908769]

32. Nokso-Koivisto J, Chonmaitree T, Jennings K, Matalon R, Block S, Patel JA. Polymorphisms of immunity genes and susceptibility to otitis media in children. PLoS One. 2014; 9(4):e93930. [PubMed: 24718616]

33. Marom T, Nokso-Koivisto J, Chonmaitree T. Viral-bacterial interactions in acute otitis media. Curr Allergy Asthma Rep. 2012; 12(6):551-8. [PubMed: 22968233]

34. Binks MJ, Cheng AC, Smith-Vaughan H, Sloots T, Nissen M, Whiley D, et al. Viral-bacterial coinfection in Australian Indigenous children with acute otitis media. BMC Infect Dis. 2011; 11:161. [PubMed: 21649905]

35. Hoberman A, Paradise JL, Rockette HE, Shaikh N, Wald ER, Kearney DH, et al. Treatment of acute otitis media in children under 2 years of age. N Engl J Med. 2011; 364(2):105-15. [PubMed: 21226576]

36. Tähtinen PA, Laine MK, Huovinen P, Jalava J, Ruuskanen O, Ruohola A. A placebo-controlled trial of antimicrobial treatment for acute otitis media. N Engl J Med. 2011; 364(2):116-26.

[PubMed: 21226577] 


\section{Key points}

- Acute otitis media occurs as a complication of symptomatic viral upper respiratory tract infection, even in the absence of nasopharyngeal bacterial colonization.

- Bacterial otopathogens and respiratory viruses interact and play important roles in acute otitis media development.

- Widespread use of bacterial and viral vaccines in young children (pneumococcal conjugate and influenza vaccines) has led to the reduction in otitis media-related health care use between years 2001 and 2011. 
Viral infection of the upper respiratory tract epithelium

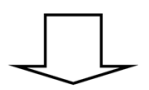

Inflammatory responses in the nasopharynx and Eustachian tube Cytokine/chemokine/ inflammatory mediator generation Increased bacterial colonization and adherence in the nasopharynx Bacterial activation and increased bacterial virulence

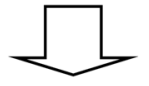

Diminished mucociliary clearance of the nasopharyngeal and tympanomastoid mucosal cells<smiles>C1CC2CCC1C2</smiles>

Eustachian tube dysfunction/ obstruction and negative middle ear pressure<smiles>C1CC2CC1C2</smiles>

Entry of the colonized bacteria and URI viruses in to the middle ear<smiles>CC1CCC(C)C1</smiles>

Immune and inflammatory responses in the middle ear<smiles>C1CC2CCC1C2</smiles>

Inflammatory changes in the middle ear mucosa and middle ear effusion

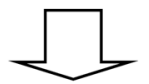

Acute otitis media signs and symptoms

Figure 1.

Simplified steps of the pathogenesis of virus-induced acute otitis media 
Table 1

Common respiratory viruses causing upper respiratory tract infection in children

\begin{tabular}{l}
\hline Adenoviruses \\
Coronaviruses \\
Enteroviruses \\
Human bocavirus type 1 \\
Human metapneumovirus \\
Influenza viruses \\
Parainfluenza viruses \\
Respiratory syncytial virus (RSV) \\
Rhinoviruses \\
\hline
\end{tabular}

로을

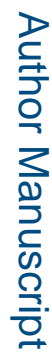

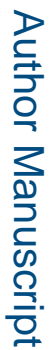

Curr Opin Pediatr. Author manuscript; available in PMC 2016 February 01. 